\title{
AS CONTRIBUIÇÕES DA BNCC PARA AS PRÁTICAS DE LINGUAGEM: MAPEANDO GENEROS DISCURSIVOS MULTISSEMIÓTICOS
}

\author{
The contributions of the BNCC for language practice: mapping \\ multisemiotics discursive genres
}

\author{
Claudemir SOUSA \\ Universidade Estadual Paulista Júlio de Mesquita Filho \\ claudemir201089@hotmail.com \\ https://orcid.org/0000-0002-5318-5040
}

RESUMO: Este trabalho discute as contribuições da Base Nacional Comum Curricular (BNCC) para o ensino das práticas de linguagem. Para tanto, analisamos o documento elaborado para o ensino médio, no qual mapeamos e discutimos as diretrizes para o ensino de língua portuguesa por meio de gêneros discursivos multissemióticos. Nosso referencial teórico está pautado nos estudos de Bakhtin (1981; 2011), sobre a linguagem como atividade interativa e sobre os gêneros do discurso; de Marcuschi (2008), sobre as práticas de leitura e produção textual; e de Gomes (2017) sobre gêneros discursivos multissemióticos. Concluímos que os gêneros discursivos multissemióticos estão presentes na BNCC atrelados a procedimentos de ensino que focalizam $o$ desenvolvimento de competência, pela mobilização de habilidades, nas quais estão integradas as práticas de leitura, escrita e escuta de textos orais, escritos e multissemióticos e a análise linguística/semiótica. Porém, a efetivação dessas práticas na sala de aula depende de uma formação por parte do professor para lidar com novos conceitos e recursos tecnológicos e da disponibilidade desses recursos aos estudantes.

PALAVRAS-CHAVE: BNCC; Práticas de linguagem; Gêneros do discurso; Multissemiose.

ABSTRACT: This article discusses the contributions of the Base Nacional Comum Curricular (BNCC) to the teaching of language practices. To this aim, we analyzed the document prepared for high school, in which we mapped and discussed the guidelines for teaching the Portuguese language through multisemiotic discursive genres. Our theoretical framework is based on Bakhtin's $(1981$; 2011) studies on language as an interactive activity and on the discursive genres; Marcuschi's (2008) discussions on reading practices and textual production; and on Gomes' (2017) studies on multisemiotic discursive genres. We concluded that multisemiotic discursive genres are present at the BNCC linked to teaching procedures that focus on the development of competence, through the mobilization of skills, in which the practices 
of reading, writing and listening to oral, written and multisemiotic texts and linguistic/semiotics analysis are integrated. However, the effectiveness of these practices in the classroom depends on teacher training to deal with new concepts and technological resources and the availability of such resources for students.

KEYWORDS: BNCC; Language practices; Discursive genres; Multisemiosis.

\section{INTRODUÇÃO}

A história do ensino de língua portuguesa na educação brasileira é marcada por reformas educacionais, que refletem os anseios do momento histórico e são fruto dos avanços econômicos, sociais, científicos e tecnológicos. Em diferentes momentos dessa história, o ensino de português na escola foi pautado por regras descontextualizadas de uso da língua, a exemplo da prescrição de regras de sintaxe, com foco na norma padrão, sem análise de contextos de uso dessas regras e suas possíveis variações. Os objetivos atuais da educação escolar colocam para os professores de Língua Portuguesa a necessidade de utilização de textos de variados gêneros discursivos e modalidades linguísticas para mediar os conteúdos que possibilitarão aos alunos aprender práticas de linguagem, auxiliados por recursos tecnológicos.

É nos anos de 1980 que surgem críticas ao ensino e à aprendizagem de língua portuguesa desvinculados do texto. Tais críticas concebem a língua como um objeto social e propugnam que o seu ensino e aprendizagem devem visar os usos sociais da linguagem (SOARES, 2002). A partir dos anos de 1990, após um longo período de ditadura militar no Brasil e com a redemocratização, foram realizadas reformas na educação, que deram origem a documentos como a Lei de Diretrizes e Bases da Educação Nacional (LDB) de 1996, a Lei no 9.394, e os Parâmetros Curriculares Nacionais (PCNs), de 1997 e 1998, com os quais a orientação teórica sócio-discursiva dos trabalhos de Bakhtin e de Vygotsky influenciaram o ensino de língua portuguesa.

A política educacional mais recente foi a aprovação da Base Nacional Comum Curricular (BNCC), a partir de um planejamento do sistema de educação (VASCONCELLOS, 2002) em nível nacional, que passou por um longo processo, marcado por polêmicas em torno de sua elaboração, dentre as quais o fato de muitas pessoas convidadas para debater esse processo não estarem vinculadas à educação básica, 
mas sim à educação superior e ao setor privado do ensino. Além disso, não há consenso entre os educadores sobre a relevância desse documento, bem como das demais diretrizes curriculares que lhes dão suporte, a exemplo das sugestões de utilização de recursos tecnológicos nas aulas, visto que muitas escolas não possuem tais suportes e tal proposta seria uma forma de agradar empresários desse setor ${ }^{1}$.

As condições em que ocorreram esses debates para a elaboração da BNCC foi de tensões políticas, que levaram à prisão de políticos e empresários e ao impeachment da então presidente Dilma Rousseff e assunção do vice, Michel Temer, mais alinhado à direita e promotor de reformas mais liberais, inclusive para a educação, que, pela utilização de recursos tecnológicos, passa a atender aos interesses de empresários.

Assim, mesmo nesse cenário de tensões, após os debates, audiências públicas e recebimento de propostas, o documento foi publicado em dois volumes: um para o ensino fundamental, publicado em 2017, e outro para o ensino médio, publicado em 2018. É esse último documento que nos interessa aqui, principalmente as suas diretrizes para o ensino de língua portuguesa, resultante de uma reforma no ensino médio efetivada com a promulgação da Lei nº 13.415/2017, que promoveu alterações na LDB nº 9.394/1996.

A BNCC do ensino médio possui quatro áreas de conhecimento, que são as seguintes, com seus respectivos componentes curriculares: Linguagem e suas Tecnologias (Arte, Educação Física, Língua Inglesa e Língua Portuguesa), Matemática e suas Tecnologias (Matemática), Ciências da Natureza e suas Tecnologias (Biologia, Física e Química) e Ciências Humanas e Sociais Aplicadas (Filosofia, Geografia, História e Sociologia). Apenas Língua Portuguesa e Matemática são disciplinas obrigatórias nos três anos do ensino médio, de acordo com a Lei ${ }^{\circ} 13.415 / 2017$.

Essa mesma Lei, em seus artigos 35 e 36, alterou a LDB para tornar real um currículo escolar com uma base nacional comum e uma parte diversificada, respeitando as peculiaridades locais, como previsto na Constituição Federal brasileira de 1988, em seus artigos 205 e 210, na LDB de 1996, em seus artigos $9^{\circ}$ e 26, e na Lei $n^{\circ} 13.005 / 2014$, que promulgou o Plano Nacional de Educação (PNE) de 2014.

A BNCC ensino médio, diferente da do ensino fundamental, propõe a construção

\footnotetext{
${ }^{1}$ Veja-se isso no seguinte link, dentre outros: $<$ https://www.unicamp.br/unicamp/ju/noticias/2017/12/04/base-curricular-e-conservadora-privatizante-eameaca-autonomia-avaliam>. Acesso em: 07 abr. 2020.
} 
de itinerários formativos, que flexibilizem a organização curricular para possibilitar opções de escolhas aos estudantes. Com isso, eles podem utilizar o tempo e o espaço escolar de forma criativa e aberta segundo os seus interesses e aspirações.

Dessa forma, o objetivo principal deste trabalho é discutir as contribuições da BNCC para as práticas de linguagem, que são as práticas de leitura, escrita e escuta de textos orais, escritos e multissemióticos e a análise linguística/semiótica. Nossos objetivos específicos são: a) mapear os gêneros discursivos multissemióticos presentes nesse documento; e b) discutir as diretrizes para o ensino de língua portuguesa com base nesses gêneros discursivos. Esse é também nosso percurso de discussão desse tema.

Este trabalho está ancorado nos estudos de Bakhtin (1981, 2011), que concebe a linguagem como atividade interativa e os gêneros do discurso como enunciados concretos pelos quais se realizam tais interações; nas contribuições de Marcuschi (2008), acerca das práticas de leitura e produção textual como atividades sócio-discursivas; e de Gomes (2017) sobre os gêneros discursivos multissemióticos como textos que combinam diferentes linguagens ou semioses.

Tais discussões teóricas orientam os documentos que norteiam o ensino de língua portuguesa no Brasil desde 1997, quando foram publicadas as primeiras edições dos PCNs, até a publicação das Diretrizes Curriculares Nacionais para o Ensino Médio (DCNEM), em 2012, revogando-os, e, posteriormente, substituídas pela BNCC, documento cuja implantação nos sistemas escolares é obrigatória e necessita que os professores se apropriem de novos conceitos e métodos nele apresentados e desenvolvam habilidades de utilizar recursos tecnológicos para inseri-los em suas aulas.

A metodologia empregada neste estudo é de cunho qualitativo, de natureza documental, no que tange à coleta dos dados, que se caracteriza, segundo Severino (2007), por utilizar como fonte documentos, escritos ou não, que não tiveram nenhum tratamento analítico, ou seja, que são ainda matéria-prima. Lakatos (2003) classifica a pesquisa documental de acordo com três variáveis: se as fontes são primárias ou secundárias, escritas ou não, e se são contemporâneas ou retrospectivas. No caso da BNCC, trata-se de fonte primária, escrita e contemporânea. Já o método de análise é uma abordagem de natureza interpretativa, na medida em que nos valemos da BNCC como um documento para discussão.

Nesse sentido, a obrigatoriedade de utilizar esse documento como diretriz para as 
aulas na educação básica justifica a necessidade deste trabalho, com o qual esperamos contribuir para ampliar a discussão sobre a utilização de gêneros do discurso na aula de Português. Feitas tais considerações, descrevemos a maneira como este trabalho está organizado.

No primeiro tópico, apresentamos as teorias que dão suporte ao nosso trabalho. Em seguida, apresentamos as análises da BNCC, destacando os gêneros do discurso multissemióticos nela presentes, a partir de cada campo de atuação e das habilidades e competências a que estão relacionados. Por fim, apresentamos as considerações finais dessa discussão, convictos de que não esgotamos as questões aqui levantadas e desejando instigar professores a lerem o documento e buscarem um referencial teórico que lhes possibilite um manejo mais autônomo e eficiente da BNCC para implementá-la em suas aulas, dentro de suas possibilidades.

\section{ENSINO DE LINGUAGEM BASEADO EM GÊNEROS DO DISCURSO: APORTES TEÓRICOS PARA O ENSINO DE LÍNGUA PORTUGUESA NO BRASIL}

Mobilizar a teoria de um autor como Bakhtin, cujos escritos datam de um momento distinto daquele no qual estamos produzindo este trabalho, requer deslocamentos teóricos que correm o risco de descontextualizar aquilo que o autor disse e enquadrar em contextos que nada têm a ver com sua "vontade de dizer" (BAKHTIN, 2011): sua teoria foi pensada, sobretudo, para gêneros literários em linguagem verbal.

Entretanto, esse é um risco necessário para falar sobre gêneros discursivos multissemióticos, veiculados em diferentes esferas de atividade, suportes textuais (MARCUSCHI, 2008) e modalidades de linguagem, que não se reduzem à fórmula "verbo-visual", na qual se destacam apenas a linguagem verbal e a visual, visto que há alguns que atrelam à dimensão visual uma dimensão oral da linguagem, a exemplo dos videoclipes e vlogs, que necessitam do ler, ver e ouvir para construir sentido.

Nas teorizações de Bakhtin acerca da linguagem emergem alguns conceitos, dos quais destacamos as noções de interação, enunciado concreto e gêneros do discurso. Primeiramente, a concepção de linguagem adotada por Bakhtin (1981) opõe-se a duas correntes de pensamento nos estudos linguísticos. Por um lado, o "subjetivismo idealista", cujo interesse é o ato de fala como uma criação individual e a língua como um sistema 
estável, por outro lado, o "objetivismo abstrato", cujo maior representante é Saussure (1988), que vê a língua como um sistema de normas gramaticais formais.

Bakhtin (1981, p. 92), por seu turno, não se volta para a língua "como um sistema de formas normativas". Para ele, a realidade fundamental da língua é constituída "pelo fenômeno social da interação verbal, realizada através da enunciação ou das enunciações" (idem, p. 123, grifos do autor). Linguagem, para esse autor, supõe diálogo e interação entre sujeitos, em uma relação que é ativa e responsiva, e não passiva.

A forma manifesta dessa interação verbal é o enunciado concreto, caracterizado por três elementos: o conteúdo temático (aquilo de que se fala no enunciado), a estrutura composicional (a sua forma de manifestação) e o estilo de linguagem (a seleção de recursos de linguagem e a relação entre parceiros da comunicação). Por isso, pode-se considerar o enunciado como a "unidade real da comunicação discursiva" (BAKHTIN, 2011, p. 269, grifos do autor).

É pela utilização de "enunciados concretos e únicos" (idem, p. 261) que ocorre a comunicação via linguagem nas diferentes atividades humanas. Além disso, sendo esse uso caracterizado pelas atividades nas quais ocorre, "cada campo de utilização da língua elabora seus tipos relativamente estáveis de enunciados, os quais denominamos gêneros do discurso" (idem, p. 262, grifos do autor), que são tão diversos quanto são diversos os campos de atividades humanas. Cada dia, novas formas de enunciados se desenvolvem acompanhando a evolução das atividades humanas.

$\mathrm{O}$ ensino/aprendizagem da linguagem mediada por gêneros do discurso na educação básica brasileira tornou-se uma diretriz a partir da publicação dos PCNs. Esses documentos estabeleciam as práticas de leitura e produção de textos escritos, escuta e produção de textos orais e análise linguística como objetivo da aprendizagem. Com a publicação da BNCC, essas diretrizes se tornam obrigatórias. No documento do ensino médio, são descritos cinco campos de utilização da linguagem, associados às práticas de linguagem trabalhadas para o desenvolvimento de competências pela mobilização de habilidades, a saber: campo da vida pessoal, campo artístico-literário, campo das práticas de estudo e pesquisa, campo jornalístico-midiático, campo de atuação na vida pública. No documento do ensino fundamental I e II, o primeiro campo é denominado de "campo da vida cotidiana".

A teoria dialógica do discurso de Bakhtin nos possibilita pensar os gêneros 
discursivos a partir dessas e outras esferas de uso da linguagem e trabalhar as práticas de linguagem sem nos restringirmos às codificações que dizem respeito apenas à palavra, uma vez que, na atualidade, os gêneros discursivos são concebidos também como multissemióticos. Com isso, mesmo as concepções de leitura e de produção textual precisam ser repensadas, para que as práticas de linguagem contemplem textos multissemióticos e a análise semiótica.

Para Marcuschi (2008), as atividades de leitura e produção de texto em uma perspectiva sócio-discursiva compreendem o texto como um evento que envolve elementos linguísticos e não linguísticos. Essas práticas de linguagem se realizam por meio de gêneros do discurso e compreende-se que a realidade fundamental do texto é a produção interativa, o que faz dele um processo em permanente elaboração, pois é necessário que alguém o processe como tal para que tenha sentido.

Dessa forma, na concepção desse autor, as práticas de leitura e produção textual são realizadas no funcionamento discursivo da linguagem. O mesmo ocorre com as práticas de escuta de textos orais e a análise linguística/semiótica, pois tais práticas de linguagem ocorrem em uma co-produção entre aquele que produz e o seu receptor. A compreensão de um texto envolve habilidades e interação, o que faz das práticas de linguagem práticas sociais, atos ativos e responsivos, como propõe Bakhtin (1981).

Quanto aos gêneros discursivos multissemióticos, Gomes (2017, p. 57) os compreende como "textos, que apresentam integração de múltiplas linguagens em suas estruturas composicionais". Esses textos vêm sendo estudados há mais de 20 anos por diversos autores do Brasil e de outros países, como Roxane Rojo e Gunther Kress, a partir de conceitos como "multissemiose" e "multimodalidade", que dizem respeito aos sistemas de linguagens ou semioses empregados na composição do texto.

$\mathrm{Na} \mathrm{BNCC}$, a semiose é conceituada como "um sistema de signos em sua organização própria" (BRASIL, 2018, p. 478). Essa organização é o que responde pelos elementos discursivos, pela composição e forma do enunciado. Assim, têm semioses sonoras, visuais, verbais e gestuais. Com as Tecnologias Digitais da Informação e da Comunicação (TDIC), os textos atuais se organizam de forma multissemiótica, ou seja, "incorporando diferentes sistemas de signos em sua constituição" (idem, 2018, p. 478).

Outras noções que também são mobilizadas para caracterizar as modalidades de linguagem envolvidas na produção do texto na contemporaneidade, caracterizada como a 
era digital, são as de "multiletramentos", "novos letramentos", e "gêneros híbridos", das quais trataremos brevemente, por não constituírem foco deste estudo. A primeira noção é oriunda das discussões do Grupo de Nova Londres, entre os quais estão Norman Fairclough, Bill Cope e Mary Kalantzis. A segunda, provém das discussões de Brian Street, Angela Kleiman e Roxane Rojo. Tais noções partem de uma concepção ampla de leitura para caracterizar os usos sociais da escrita dentro e fora da sala de aula, em diferentes atividades, como pegar um ônibus, utilizar um caixa eletrônico, etc.

Já a noção de "gêneros híbridos" é desenvolvida pelos leitores contemporâneos de Bakhtin, como Jay L. Lemke, para caracterizar a maneira como se articulam o oral, o escrito, o visual, etc., nos gêneros discursivos contemporâneos. Em nossas discussões, interessam, particularmente, os gêneros discursivos multissemióticos, presentes nas mais variadas esferas da atividade (BAKHTIN, 2011), que a BNCC propõe para o ensino de práticas de linguagem na aula de Língua Portuguesa. Esses textos utilizam várias semioses, na medida em que essas práticas de linguagem estão interligadas, integrando diferentes sistemas de signos e recorrendo a diferentes recursos tecnológicos.

Por essa razão, a efetivação dessas diretrizes necessita da difusão de um referencial teórico que instrumentalize os docentes a lidarem com novos conceitos, inclusive alguns que estão em campos teóricos distintos da sua formação. É preciso assumir uma postura indisciplinar, que Moita Lopes $(2009$; 2011) classifica como a ruptura com as fronteiras entre as disciplinas, na busca por um referencial teórico que possibilite falar para o sujeito de nosso tempo. Na sua concepção, as teorias das diversas disciplinas não dão conta de falar para o mundo de hoje, já que foram formuladas em outros contextos. Com isso, as discussões sobre o ensino de língua formuladas em contextos do passado precisam ser repensadas para poder dar respostas aos problemas atuais que envolvem linguagem e tecnologia. São essas questões que discutimos adiante, conforme proposto.

\section{OS GÊNEROS DO DISCURSO MULTISSEMIÓTICOS NA BNCC: MAPEANDO CONCEITOS E PROCEDIMENTOS}

A BNCC define as aprendizagens essenciais para todos os estudantes nas diferentes etapas e modalidades da educação básica, propondo o desenvolvimento de dez (10) competências gerais. O conceito de competência é compreendido como a 
“mobilização de conhecimentos (conceitos e procedimentos), habilidades (práticas, cognitivas e socioemocionais), atitudes e valores para resolver demandas complexas da vida cotidiana, do pleno exercício da cidadania e do mundo do trabalho" (BRASIL, 2018, p. 8). Esses conceitos de competências e habilidades não mencionam as práticas de linguagem e se distanciam de uma concepção de língua pautada em Bakhtin. Essas competências são descritas no documento conforme o quadro que segue:

Tabela 1: Competências gerais da Educação Básica

\begin{tabular}{|c|c|}
\hline 1 & $\begin{array}{l}\text { Valorizar e utilizar os conhecimentos historicamente construídos sobre o mundo físico, } \\
\text { social, cultural e digital para entender e explicar a realidade, continuar aprendendo e } \\
\text { colaborar para a construção de uma sociedade justa, democrática e inclusiva. }\end{array}$ \\
\hline 2 & $\begin{array}{l}\text { Exercitar a curiosidade intelectual e recorrer à abordagem própria das ciências, incluindo a } \\
\text { investigação, a reflexão, a análise crítica, a imaginação e a criatividade, para investigar } \\
\text { causas, elaborar e testar hipóteses, formular e resolver problemas e criar soluções (inclusive } \\
\text { tecnológicas) com base nos conhecimentos das diferentes áreas. }\end{array}$ \\
\hline 3 & $\begin{array}{l}\text { ais, das locais às mundiais, } \mathrm{e} \\
\text { ico-cultural. }\end{array}$ \\
\hline 4 & $\begin{array}{l}\text { Utilizar diferentes linguagens - verbal (oral ou visual-motora, como Libras, e escrita), } \\
\text { corporal, visual, sonora e digital -, bem como conhecimentos das linguagens artística, } \\
\text { matemática e científica, para se expressar e partilhar informações, experiências, ideias e } \\
\text { sentimentos em diferentes contextos e produzir sentidos que levem ao entendimento mútuo. }\end{array}$ \\
\hline 5 & $\begin{array}{l}\text { Compreender, utilizar e criar tecnologias digitais de informação e comunicação de forma } \\
\text { crítica, significativa, reflexiva e ética nas diversas práticas sociais (incluindo as escolares) } \\
\text { para se comunicar, acessar e disseminar informações, produzir conhecimentos, resolver } \\
\text { problemas e exercer protagonismo e autoria na vida pessoal e coletiva. }\end{array}$ \\
\hline 6 & $\begin{array}{l}\text { Valorizar a diversidade de saberes e vivências culturais e apropriar-se de conhecimentos e } \\
\text { experiências que lhe possibilitem entender as relações próprias do mundo do trabalho e } \\
\text { fazer escolhas alinhadas ao exercício da cidadania e ao seu projeto de vida, com liberdade, } \\
\text { autonomia, consciência crítica e responsabilidade. }\end{array}$ \\
\hline 7 & $\begin{array}{l}\text { Argumentar com base em fatos, dados e informações confiáveis, para formular, negociar e } \\
\text { defender ideias, pontos de vista e decisões comuns que respeitem e promovam os direitos } \\
\text { humanos, a consciência socioambiental e o consumo responsável em âmbito local, regional } \\
\text { e global, com posicionamento ético em relação ao cuidado de si mesmo, dos outros e do } \\
\text { planeta. }\end{array}$ \\
\hline 8 & $\begin{array}{l}\text { Conhecer-se, apreciar-se e cuidar de sua saúde física e emocional, compreendendo-se na } \\
\text { diversidade humana e reconhecendo suas emoções e as dos outros, com autocrítica e } \\
\text { capacidade para lidar com elas. }\end{array}$ \\
\hline 9 & $\begin{array}{l}\text { Exercitar a empatia, o diálogo, a resolução de conflitos e a cooperação, fazendo-se respeitar } \\
\text { e promovendo o respeito ao outro e aos direitos humanos, com acolhimento e valorização da } \\
\text { diversidade de indivíduos e de grupos sociais, seus saberes, identidades, culturas e } \\
\text { potencialidades, sem preconceitos de qualquer natureza. }\end{array}$ \\
\hline 10 & $\begin{array}{l}\text { Agir pessoal e coletivamente com autonomia, responsabilidade, flexibilidade, resiliência e } \\
\text { determinação, tomando decisões com base em princípios éticos, democráticos, inclusivos, } \\
\text { sustentáveis e solidários. }\end{array}$ \\
\hline
\end{tabular}

Fonte: BRASIL (2018, p. 9-10). 
Nessas competências, há uma rearticulação da forma de associação das três dimensões do conhecimento, que são: conceitos, procedimentos e atitudes (ZABALA, 1998). A linguagem está presente em todas elas, embora sejamos levados a acreditar que apenas a competência 4 está relacionada à área de linguagem, por ser aquela na qual esse termo é expresso. Ocorre que, conforme Bakhtin (2011), todas as atividades humanas demandam a utilização da linguagem e essas atividades se estruturam por meio dos gêneros do discurso.

No documento, há também a descrição de competências específicas de cada área, que serão relacionadas a um conjunto de habilidades de cada componente curricular, que devem ser desenvolvidas pelos alunos. As competências específicas são as que seguem:

Tabela 2: Competências específicas de Linguagens e suas Tecnologias para o Ensino Médio

1 Compreender o funcionamento das diferentes linguagens e práticas (artísticas, corporais e verbais) e mobilizar esses conhecimentos na recepção e produção de discursos nos diferentes campos de atuação social e nas diversas mídias, para ampliar as formas de participação social, o entendimento e as possibilidades de explicação e interpretação crítica da realidade e para continuar aprendendo.

2 Compreender os processos identitários, conflitos e relações de poder que permeiam as práticas sociais de linguagem, respeitar as diversidades, a pluralidade de ideias e posições e atuar socialmente com base em princípios e valores assentados na democracia, na igualdade e nos Direitos Humanos, exercitando a empatia, o diálogo, a resolução de conflitos e a cooperação, e combatendo preconceitos de qualquer natureza.

3 Utilizar diferentes linguagens (artísticas, corporais e verbais) para exercer, com autonomia e colaboração, protagonismo e autoria na vida pessoal e coletiva, de forma crítica, criativa, ética e solidária, defendendo pontos de vista que respeitem o outro e promovam os Direitos Humanos, a consciência socioambiental e o consumo responsável, em âmbito local, regional e global.

4 Compreender as línguas como fenômeno (geo)político, histórico, social, variável, heterogêneo e sensível aos contextos de uso, reconhecendo-as e vivenciando-as como formas de expressões identitárias, pessoais e coletivas, bem como respeitando as variedades linguísticas e agindo no enfrentamento de preconceitos de qualquer natureza.

5 Compreender os múltiplos aspectos que envolvem a produção de sentidos nas práticas sociais da cultura corporal de movimento, reconhecendo-as e vivenciando-as como formas de expressão de valores e identidades, em uma perspectiva democrática e de respeito à diversidade.

6 Apreciar esteticamente as mais diversas produções artísticas e culturais, considerando suas características locais, regionais e globais, e mobilizar seus conhecimentos sobre as linguagens artísticas para dar significado e (re)construir produções autorais individuais e coletivas, de maneira crítica e criativa, com respeito à diversidade de saberes, identidades e culturas.

7 Mobilizar práticas de linguagem no universo digital, considerando as dimensões técnicas, críticas, criativas, éticas e estéticas, para expandir as formas de produzir sentidos, de engajar-se em práticas autorais e coletivas, e de aprender a aprender nos campos da ciência, cultura, trabalho, informação e vida pessoal e coletiva.

Fonte: BRASIL (2018, p. 481-482). 
Essas competências não contemplam cada componente da área de Linguagem e suas Tecnologias de forma individualizada, mesmo que a competência 4 seja aquela que mencione o termo "língua". Todas elas são associadas às habilidades específicas do componente curricular Língua Portuguesa, incluindo as que demandam a utilização de ferramentas tecnológicas e o trabalho com gêneros discursivos multissemióticos, propugnando atividades individuais e coletivas nas quais se aprendam conceitos e habilidades de forma crítica, criativa, ética e solidária, como consta na tabela anterior.

Como já dissemos, tais gêneros estão organizados por cinco (5) campos de atuação social, denominação que equivale às esferas da atividade humana, conforme cunhou Bakhtin (2011). Essa proposta busca “contextualizar as práticas de linguagem” (BRASIL, 2018, p. 493), compreendidas como eixos de integração dos conteúdos.

Adiante, apresentamos as habilidades para trabalhar gêneros multissemióticos por campo de atuação. Para facilitar a compreensão, ressalte-se que tais habilidades são identificadas com um código alfanumérico, do tipo EM13LP11, em que, no exemplo dado, o primeiro par de letras (EM) indica a etapa do Ensino Médio, os dois primeiros números (13) indicam que as habilidades podem ser desenvolvidas em qualquer das três séries dessa etapa, o segundo par de letras (LP) indica o componente curricular, os números finais (11) indicam a competência específica à qual se relaciona a habilidade (primeiro número) e sua numeração no conjunto de habilidades relativas a cada competência (último número), como segue.

a) Todos os campos de atuação social

Tabela 3: Habilidades do componente curricular língua portuguesa comuns a todos os campos de atuação social

\section{TODOS OS CAMPOS DE ATUAÇÃO SOCIAL}

PRÁTICAS DE LINGUAGEM: Leitura, escuta, produção de textos (orais, escritos, multissemióticos) e análise linguística/semiótica

Habilidades

Competências

Específicas

(EM13LP10) Selecionar informações, dados e argumentos em fontes confiáveis, impressas e digitais, e utilizá-los de forma referenciada, para que o texto a ser 1,7 produzido tenha um nível de aprofundamento adequado (para além do senso comum) e contemple a sustentação das posições defendidas. 
EM13LP12) Analisar efeitos de sentido decorrentes de escolhas e formatação das imagens (enquadramento, ângulo/vetor, cor, brilho, contraste) e de sua sequenciação (disposição e transição, movimentos de câmera, remix), das performances (movimentos do corpo, gestos, ocupação do espaço cênico), dos elementos sonoros (entonação, trilha sonora, sampleamento etc.) e das relações desses elementos com o verbal, levando em conta esses efeitos nas produções de imagens e vídeos, para ampliar as possibilidades de construção de sentidos e de apreciação.

(EM13LP13) Planejar, produzir, revisar, editar, reescrever e avaliar textos escritos e multissemióticos, considerando sua adequação às condições de produção do texto, no que diz respeito ao lugar social a ser assumido e à imagem que se pretende passar a respeito de si mesmo, ao leitor pretendido, ao veículo e mídia em que o texto ou produção cultural vai circular, ao contexto imediato e sócio-histórico mais geral, ao gênero textual em questão e suas regularidades, à variedade linguística apropriada a esse contexto e ao uso do conhecimento dos aspectos notacionais (ortografia padrão, pontuação adequada, mecanismos de concordância nominal e verbal, regência verbal etc.), sempre que o contexto o exigir.

(EM13LP15) Elaborar roteiros para a produção de vídeos variados ( $v \log$, videoclipe, videominuto, documentário etc.), apresentações teatrais, narrativas multimídia e transmídia, podcasts, playlists comentadas etc., para ampliar as possibilidades de produção de sentidos e engajar-se de forma reflexiva em práticas autorais e coletivas. (EM13LP16) Utilizar softwares de edição de textos, fotos, vídeos e áudio, além de ferramentas e ambientes colaborativos para criar textos e produções multissemióticas com finalidades diversas, explorando os recursos e efeitos disponíveis e apropriandose de práticas colaborativas de escrita, de construção coletiva do conhecimento e de desenvolvimento de projetos.

Fonte: BRASIL (2018, p. 499-500).

\begin{tabular}{|l|}
1 \\
1,3 \\
3,7 \\
7 \\
\hline
\end{tabular}

b) Campo da vida pessoal

Tabela 4: Habilidades do componente curricular língua portuguesa do campo da vida pessoa

\begin{tabular}{|c|c|}
\hline \multicolumn{2}{|l|}{ CAMPO DA VIDA PESSOAL } \\
\hline \multicolumn{2}{|c|}{$\begin{array}{l}\text { PRÁTICAS DE LINGUAGEM: Leitura, escuta, produção de textos (orais, escritos, multissemióticos) } \\
\text { e análise linguística/semiótica }\end{array}$} \\
\hline Habilidades & $\begin{array}{l}\text { Competências } \\
\text { específicas }\end{array}$ \\
\hline $\begin{array}{l}\text { (EM13LP18) Apresentar-se por meio de textos multimodais diversos (perfis } \\
\text { variados, gifs biográficos, biodata, currículo web, videocurrículo etc.) e de } \\
\text { ferramentas digitais (ferramenta de gif, wiki, site etc.), para falar de si de formas } \\
\text { variadas, considerando diferentes situações e objetivos. }\end{array}$ & 3 \\
\hline $\begin{array}{l}\text { (EM13LP20) Produzir, de forma colaborativa, e socializar playlists comentadas de } \\
\text { preferências culturais e de entretenimento, revistas culturais, fanzines, e-zines ou } \\
\text { publicações afins que divulguem, comentem e avaliem músicas, games, séries, } \\
\text { filmes, quadrinhos, livros, peças, exposições, espetáculos de dança etc., de forma a } \\
\text { compartilhar gostos, identificar afinidades, fomentar comunidades etc. }\end{array}$ & 1,6 \\
\hline
\end{tabular}

Fonte: BRASIL (2018, p. 502). 
c) Campo de atuação na vida pública

Tabela 5: Habilidades do componente curricular língua portuguesa do campo de atuação na vida pública

CAMPO DE ATUAÇÃO NA VIDA PÚBLICA
$\begin{aligned} & \text { PRÁTICAS DE LINGUAGEM: Leitura, escuta, produção de textos (orais, escritos, multissemióticos) } \\
& \text { e análise linguística/semiótica }\end{aligned}$
\begin{tabular}{ll} 
Habilidades & $\begin{array}{c}\text { Competências } \\
\text { específicas }\end{array}$ \\
\hline $\begin{array}{l}\text { (EM13LP22) Analisar o histórico e o discurso político de candidatos e de partidos, } \\
\text { como também propagandas políticas e programas e propostas de governo, de forma a } \\
\text { participar do debate político e tomar decisões fundamentadas. }\end{array}$ & 1,7 \\
\hline
\end{tabular}

Fonte: BRASIL (2018, p. 505).

d) Campo das práticas de estudo e pesquisa

Tabela 6: Habilidades do componente curricular língua portuguesa do campo das prática de estudo e pesquisa

\begin{tabular}{|c|c|}
\hline \multicolumn{2}{|c|}{$\begin{array}{l}\text { CAMPO DAS PRÁTICAS DE ESTUDO E PESQUISA } \\
\text { PRÁTICAS DE LINGUAGEM: Leitura, escuta, produção de textos (orais, escritos, multissemióticos) } \\
\text { e análise linguística/semiótica }\end{array}$} \\
\hline Habilidades & $\begin{array}{l}\text { Competências } \\
\text { específicas }\end{array}$ \\
\hline $\begin{array}{l}\text { (EM13LP30) Compreender criticamente textos de divulgação científica orais, } \\
\text { escritos e multissemióticos de diferentes áreas do conhecimento, identificando sua } \\
\text { organização tópica e a hierarquização das informações, questionando fontes não } \\
\text { confiáveis e problematizando enfoques tendenciosos ou superficiais. }\end{array}$ & 1 \\
\hline $\begin{array}{l}\text { (EM13LP33) Produzir textos para a divulgação do conhecimento e de resultados } \\
\text { de levantamentos e pesquisas - texto monográfico, ensaio, artigo de divulgação } \\
\text { científica, verbete de enciclopédia (colaborativa ou não), infográfico (estático ou } \\
\text { animado), relato de experimento, relatório, relatório multimidiático de campo, } \\
\text { reportagem científica, podcast ou vlog científico, apresentações orais, seminários, } \\
\text { comunicações em mesas redondas, mapas dinâmicos etc. -, considerando o } \\
\text { contexto de produção e utilizando os conhecimentos sobre os gêneros de } \\
\text { divulgação científica, de forma a engajar-se em processos significativos de } \\
\text { socialização e divulgação do conhecimento. }\end{array}$ & 3 \\
\hline $\begin{array}{l}\text { (EM13LP34) Utilizar adequadamente ferramentas de apoio a apresentações orais, } \\
\text { escolhendo e usando tipos e tamanhos de fontes que permitam boa visualização, } \\
\text { topicalizando e/ou organizando o conteúdo em itens, inserindo de forma adequada } \\
\text { imagens, gráficos, tabelas, formas e elementos gráficos, dimensionando a } \\
\text { quantidade de texto e imagem por slide e usando, de forma harmônica, recursos } \\
\text { (efeitos de transição, slides mestres, layouts personalizados, gravação de áudios } \\
\text { em slides etc.). }\end{array}$ & 7 \\
\hline
\end{tabular}

Fonte: BRASIL (2018, p. 508-509). 
e) Campo jornalístico-midiático

Tabela 7: Habilidades do componente curricular língua portuguesa do campo jornalísticomidiático

\begin{tabular}{|c|c|}
\hline \multicolumn{2}{|c|}{$\begin{array}{l}\text { CAMPO JORNALÍSTICO-MIDIÁTICO } \\
\text { PRÁTICAS DE LINGUAGEM: Leitura, escuta, produção de textos (orais, escritos, multissemióticos) } \\
\text { e análise linguística/semiótica }\end{array}$} \\
\hline Habilidades & $\begin{array}{l}\text { Competências } \\
\text { específicas }\end{array}$ \\
\hline $\begin{array}{l}\text { (EM13LP35) Analisar os interesses que movem o campo jornalístico, os impactos } \\
\text { das novas tecnologias no campo e as condições que fazem da informação uma } \\
\text { mercadoria e da checagem de informação uma prática (e um serviço) essencial, } \\
\text { adotando atitude analítica e crítica diante dos textos jornalísticos. }\end{array}$ & 2 \\
\hline $\begin{array}{l}\text { (EM13LP38) Usar procedimentos de checagem de fatos noticiados e fotos } \\
\text { publicadas (verificar/avaliar veículo, fonte, data e local da publicação, autoria, URL, } \\
\text { formatação; comparar diferentes fontes; consultar ferramentas e sites checadores } \\
\text { etc.), de forma a combater a proliferação de notícias falsas (fake news). }\end{array}$ & 7 \\
\hline $\begin{array}{l}\text { (EM13LP41) Acompanhar, analisar e discutir a cobertura da mídia diante de } \\
\text { acontecimentos e questões de relevância social, local e global, comparando } \\
\text { diferentes enfoques e perspectivas, por meio do uso de ferramentas de curadoria de } \\
\text { informação (como agregadores de conteúdo) e da consulta a serviços e fontes de } \\
\text { checagem e curadoria de informação, de forma a aprofundar o entendimento sobre } \\
\text { um determinado fato ou questão, identificar o enfoque preponderante da mídia e } \\
\text { manter-se implicado, de forma crítica, com os fatos e as questões que afetam a } \\
\text { coletividade. }\end{array}$ & 2 \\
\hline $\begin{array}{l}\text { (EM13LP42) Atuar de forma fundamentada, ética e crítica na produção e no } \\
\text { compartilhamento de comentários, textos noticiosos e de opinião, memes, gifs, } \\
\text { remixes variados etc. em redes sociais ou outros ambientes digitais. }\end{array}$ & 7 \\
\hline $\begin{array}{l}\text { (EM13LP43) Analisar formas contemporâneas de publicidade em contexto } \\
\text { digital e peças de campanhas publicitárias e políticas (cartazes, folhetos, } \\
\text { anúncios, propagandas em diferentes mídias, spots, jingles etc.), explicando } \\
\text { os mecanismos de persuasão utilizados e os efeitos de sentido provocados } \\
\text { pelas escolhas feitas em termos de elementos e recursos linguístico- } \\
\text { discursivos, imagéticos, sonoros, gestuais e espaciais, entre outros, e } \\
\text { destacando valores e representações de situações, grupos e configurações } \\
\text { sociais veiculadas, a fim de desconstruir eventuais estereótipos e proceder a } \\
\text { uma avaliação crítica da publicidade e das práticas de consumo. }\end{array}$ & 1,7 \\
\hline $\begin{array}{l}\text { (EM13LP44) Analisar, discutir, produzir e socializar, tendo em vista temas e } \\
\text { acontecimentos de interesse local ou global, notícias, fotodenúncias, } \\
\text { fotorreportagens, reportagens multimidiáticas, documentários, infográficos, podcasts } \\
\text { noticiosos, artigos de opinião, críticas da mídia, vlogs de opinião, textos de } \\
\text { apresentação e apreciação de produções culturais (resenhas, ensaios etc.) e outros } \\
\text { gêneros próprios das formas de expressão das culturas juvenis (vlogs e podcasts } \\
\text { culturais, gameplay etc.), em várias mídias, vivenciando de forma significativa o } \\
\text { papel de repórter, analista, crítico, editorialista ou articulista, leitor, vlogueiro e } \\
\text { booktuber, entre outros. }\end{array}$ & 1,3 \\
\hline
\end{tabular}

Fonte: BRASIL (2018, p. 511-512). 
f) Campo artístico-literário

Tabela 8: Habilidades do componente curricular língua portuguesa do campo artístico-literário

\begin{tabular}{|c|c|}
\hline \multicolumn{2}{|l|}{ CAMPO ARTÍSTICO-LITERÁRIO } \\
\hline \multicolumn{2}{|c|}{$\begin{array}{l}\text { PRÁTICAS DE LINGUAGEM: Leitura, escuta, produção de textos (orais, escritos, multissemióticos) } \\
\text { e análise linguística/semiótica }\end{array}$} \\
\hline Habilidades & $\begin{array}{l}\text { Competências } \\
\text { específicas }\end{array}$ \\
\hline $\begin{array}{l}\text { (EM13LP46) Participar de eventos (saraus, competições orais, audições, mostras, } \\
\text { festivais, feiras culturais e literárias, rodas e clubes de leitura, cooperativas culturais, } \\
\text { jograis, repentes, slams etc.), inclusive para socializar obras da própria autoria } \\
\text { (poemas, contos e suas variedades, roteiros e microrroteiros, videominutos, playlists } \\
\text { comentadas de música etc.) e/ou interpretar obras de outros, inserindo-se nas } \\
\text { diferentes práticas culturais de seu tempo. }\end{array}$ & 3,6 \\
\hline $\begin{array}{l}\text { (EM13LP52) Produzir apresentações e comentários apreciativos e críticos sobre } \\
\text { livros, filmes, discos, canções, espetáculos de teatro e dança, exposições etc. } \\
\text { (resenhas, vlogs e podcasts literários e artísticos, playlists comentadas, fanzines, } e \text { - } \\
\text { zines etc.). }\end{array}$ & 1,3 \\
\hline $\begin{array}{l}\text { (EM13LP53) Criar obras autorais, em diferentes gêneros e mídias - mediante } \\
\text { seleção e apropriação de recursos textuais e expressivos do repertório artístico -, } \\
\text { e/ou produções derivadas (paródias, estilizações, fanfics, fanclipes etc.), como forma } \\
\text { de dialogar crítica e/ou subjetivamente com o texto literário. }\end{array}$ & 1,3 \\
\hline
\end{tabular}

Fonte: BRASIL (2018, p. 516-516).

Nos quadros precedentes, destacamos apenas as habilidades que objetivam trabalhar gêneros multissemióticos. Façamos, agora, algumas considerações sobre essas diretrizes para o trabalho com as práticas de linguagem por meio desses gêneros nas cinco (5) esferas da atividade (BAKHTIN, 1981) mencionadas na BNCC. Primeiramente, destaca-se que todas as habilidades desse componente são apresentadas sem indicação de seriação, já que são previstas para serem trabalhadas nos três anos do Ensino Médio. Com isso, fica a cargo das escolas indicar as suas formas de progressão.

Em segundo lugar, caracterizamos cada campo brevemente, destacando um dos gêneros multissemióticos neles trabalhados. $O$ primeiro é o campo da vida pessoal, que possibilita refletir sobre as condições da vida contemporânea, sobre a juventude no Brasil e no mundo, sobre questões que envolvem os jovens, o que implica uma leitura crítica da realidade. As atividades propostas para esse campo possibilitam uma reflexão sobre projetos de vida, combinada a diferentes atitudes.

Para tanto, um dos gêneros multissemióticos indicados são os gifs (Graphics Interchange Format), que são uma "mídia essencialmente visual, não apresentando 
qualquer som, caracterizados, primordialmente, por uma estratégia de repetição incessante de uma imagem" (MILANEZ, 2018, p. 118). Essas imagens animadas e sem som são utilizadas com variados propósitos comunicativos, principalmente nas redes sociais como forma de humor, e também para falarmos de nossas angústias, nossos medos e nossas paixões, podendo ser utilizados nas aulas por já estarem inseridos no dia-a-dia dos alunos que utilizam redes sociais com mais frequência.

Existem dois sites de gifs mais visitados e cujos conteúdos são os que mais circulam nas mídias digitais, a saber: o www.tumlr.com e o www.giphy.com. O trabalho com gifs na escola, objetivando falar de si mesmo, requer conhecimento de informática e habilidade para utilizar tecnologias digitais, como computadores, smartphones, e tablets, além da disponibilidade de tais recursos dentro e fora da escola, para que a prescrição dessa atividade não se torne uma exclusão dos alunos menos favorecidos economicamente e que não dispõe de aparelhos tecnológicos e acesso à internet.

A segunda esfera da atividade (BAKHTIN, 1981) é o campo de atuação na vida pública, constituído por textos normativos, legais, jurídicos, que regulam a vida em sociedade, o que permite aos alunos refletirem sobre a vida pública e a ética das relações. Essa atividade requer um processo interdisciplinar, no qual a leitura de textos das esferas jurídicas possibilita um olhar crítico para a realidade e a construção do estudante como cidadão conhecedor de seus direitos, pressupondo também leituras do professor.

Um dos gêneros discursivos multissemióticos que destacamos para o trabalho nesse campo são as propagandas políticas, gênero que, atualmente, circula em diferentes suportes textuais (MARCUSCHI, 2008), como as mídias impressas e as redes sociais digitais, e se constituem por diferentes semioses. Ao longo do tempo, a propaganda política sofreu grandes transformações, não só no aspecto composicional, como também no estilo de linguagem, para integrar as estratégias da sociedade de consumo (COURTINE, 2003), o que implica a necessidade de o professor conhecer as questões que os estudiosos desse gênero vêm discutindo e discutir com os alunos, que já participam ou irão participar das escolhas políticas de forma mais crítica.

Quanto ao campo das práticas de estudo e pesquisa, abrange a pesquisa, produção, apreciação, etc., de textos que circulam na esfera escolar e acadêmica, assim como textos de pesquisa e de divulgação científica. Esses textos possibilitam refletir sobre as linguagens e a construção de conhecimento científico. O contato dos alunos com esses 
textos, possibilita o domínio de gêneros que normalmente ficam restritos ao nível superior. Assim, as práticas de linguagem poderão conduzir a uma elaboração de textos adequados às normas técnicas científicas ainda no ensino médio.

Um dos gêneros discursivos multissemióticos indicados para trabalhar nesse campo da atividade (BAKHTIN, 1981) são os vlogs, abreviatura para "videoblogue", que são blogs ou páginas web de teor pessoal, cujo conteúdo principal são vídeos. No caso em questão, trata-se de um vlog científico, que irá requerer o emprego de outro estilo de linguagem por parte do aluno para tratar de diferentes conteúdos escolares.

Já no campo jornalístico-midiático, tem-se textos de circulação na mídia informativa e na publicidade. A leitura desses textos possibilita uma reflexão crítica aos alunos acerca das informações que circulam entre nós, além de prepará-los para uma seleção mais consciente dos conteúdos que irão consumir. Atualmente, fala-se muito em fake news (notícias falsas) e pós-verdade e o ensino de gêneros dessa esfera precisa ser reteorizado, pois não se pode mais conceber as notícias como um gênero objetivo e verdadeiro, como consta em alguns livros didáticos, pois a própria verdade é uma construção histórica (FOUCAULT, 2013), que serve a certos propósitos sociais.

Um dos gêneros indicados para trabalhar nesse campo são os memes, que consistem em um texto verbo-visual de teor satírico, podendo também ser um vídeo ou áudio largamente compartilhado. Além de gênero, o meme também pode ser pensado como um fenômeno da internet no qual se propaga um conceito em forma de hiperlink, vídeo, imagem, website, hashtag, (palavra precedida de \# que sintetiza um conteúdo em pauta) ou apenas uma palavra ou frase, através das redes sociais, blogs, sites, e-mail ou outros serviços de web, ou suportes textuais (SOUSA, 2015).

Finalmente, no campo artístico-literário, circulam as manifestações artísticas em geral, que os alunos poderão fruir, produzir, valorizar, com base em critérios estéticos e no exercício da sensibilidade. Essas são as habilidades que os alunos deverão mobilizar no trabalho com as mais variadas práticas de linguagem com os gêneros multissemióticos, dentre os quais destacamos uma forma de apropriação do discurso alheio (BAKHTIN, 1981): as narrativas transmídia.

As narrativas transmídia são definidas por Jenkins (2009, p. 108) como um jogo no qual uma história se desenrola "através de múltiplas plataformas de mídia, com cada novo texto contribuindo de maneira distinta e valiosa para o todo". Trata-se de formas de 
apropriação de um enunciado primeiro, como filmes, dos quais os estudantes podem fazer uma narrativa diferente. Esse procedimento se chama "remidiação", ou seja, migração de um enunciado de uma mídia a outra. A web possibilita a aceleração desse processo de intercâmbio de um artefato cultural em diversas mídias. Assim, personagens de um livro que os alunos já leram podem aparecer no cinema, na televisão, em estampas, além de ganhar versões narrativas feitas por eles mesmos, em uma atividade que pressupõe a integração de diversas práticas de linguagem.

Esse fenômeno está ligado a outro, que Jenkins (2009) denomina de convergência das mídias, que potencializa o uso das mídias para a construção de sentidos. A cultura da convergência se caracteriza pela colisão entre as novas e as velhas mídias, pelo cruzamento entre as mídias corporativas e as mídias alternativas e pela interação entre o poder do produtor de mídia e o poder do consumidor.

A convergência se relaciona com a cultura participativa e a inteligência coletiva. A cultura participativa é a atribuição de um papel ativo ao consumidor/espectador dos meios de comunicação, que passa também a ser um produtor, mesmo que essa participação seja desigual entre tais sujeitos. Já a inteligência coletiva, segundo Jenkins (2009), caracteriza o consumo como um processo coletivo, uma fonte alternativa de poder midiático.

Com vemos, o ensino das práticas de linguagem ganha maiores possibilidades com os gêneros multissemióticos e a utilização de ferramentas tecnológicas, ao menos na teoria, mas não necessariamente se pode dizer que tais possibilidades são um avanço ou uma exclusão, visto que as condições sociais da escola, dos professores e dos alunos é que irão determinar a aplicabilidade ou não dessas diretrizes na sala de aula.

Além desses gêneros discursivos (BAKHTIN, 2011), sublinhamos também as fanzines, que são publicações em revistas (magazines) não oficiais, feitas por fãs de cinema ou música; as e-zines, que são as fanzines eletrônicas, compartilhadas em sites ou e-mails; as fanfics, que são versões de textos literários feitas por fãs, possibilitando ressignificar o trabalho com a literatura; o podcast, que consiste em arquivo de áudio com conteúdo informativo disponibilizado em uma página web para ser compartilhado; os wiki, que consistem em sites nos quais os utilizadores podem modificar os conteúdos compartilhados e realizar uma escrita colaborativa; e o spot, uma peça publicitária utilizada na rádio para transmitir uma grande quantidade de informações em uma só mensagem, podendo também estar a serviço dos propósitos educacionais. 
Dessa forma, embora esse documento mencione apenas cinco (5) campos de atuação, a utilização da linguagem está para além dessas esferas, já que ela ocorre em todas as atividades humanas, consoante Bakhtin (2011). As habilidades para o trabalho com esses gêneros são diversas e, ao serem agrupadas nesses campos da atividade, possibilitam uma organização curricular mais indisciplinar, tal como nos instiga Moita Lopes (2011), pois possibilitam integrar as linguagens pela experiência dos alunos com diferentes mídias, que lhes conferem uma experiência significativa. Para tanto, novas ações e procedimentos são necessários, o que implica a mobilização de novas habilidades, que conduzirão a diferentes competências.

Entretanto, mesmo que a BNCC intencione contribuir para a expansão do repertório linguístico, cultural e multissemiótico dos alunos, com reflexão crítica, criativa, ética e solidária sobre os usos sociais da linguagem em seus vários campos de atividade, como é dito explicitamente no documento em várias partes, como na descrição das competências específicas para a área de Linguagens e suas Tecnologias (BRASIL, 2018, p. 481-482), para que isso ocorra, o professor precisará compreender essas diretrizes no conjunto dessa variedade de elementos: gêneros discursivos, procedimentos para o trabalho com eles, práticas de linguagem, competências e campos de atuação.

A teoria dialógica do discurso de Bakhtin, tal como relida por seus interlocutores contemporâneos, fornece-nos essa base conceitual, mas é necessária uma adequação às possibilidades materiais das escolas e às capacidades dos alunos para usufruírem dessas práticas de linguagem, pois o uso de tecnologias digitais nas escolas não é uma realidade de todo o território brasileiro.

Em 2020, devido à pandemia causada pelo corona vírus, as atividades escolares foram paralisadas no Brasil em março e isso tornou mais evidente a desigualdade social no acesso à educação e ao uso de tecnologias, pois a regra de distanciamento social foi estabelecida como medida de contenção dos contágios pelo vírus e muitas escolas públicas não tiveram como dar aulas online para os alunos. A razão para isso era a falta de recursos tecnológicos e de acesso à rede mundial de computadores por parte de muitos alunos e professores e da inabilidade com esse novo formato de aula.

Assim, espera-se que esse trabalho possa contribuir para os professores, que deverão, a partir de 2020, incorporar a BNCC ao seu cotidiano escolar, sobretudo em um momento em que a tecnologia se tornou mais premente no cotidiano educacional, em que 
a regência da sala de aula migrou para as casas dos professores, que transmitem suas aulas para a web e dessa são reenviadas para as residências dos alunos.

\section{CONSIDERAÇÕES FINAIS}

A BNCC do ensino médio se baseia em procedimentos que possibilitam ao aluno desenvolver uma série de habilidades e aprofundar outras já desenvolvidas no ensino fundamental. Com isso, espera-se que ele possa participar de diversas práticas de linguagem, pois além de já dominar alguns gêneros discursivos de diferentes campos de atuação social, ele vai se envolver em outras práticas, com gêneros multisssemióticos.

A cultura digital ganha destaque no ensino médio, mas não se pode acreditar que a simples prescrição curricular irá implicar em efetivação na realidade das escolas. Para as práticas de linguagem, são sugeridas atividades interativas, colaborativas e dialógicas com a utilização de mídias, nas quais as informações circulam em diferentes gêneros discursivos multissemióticos. Alguns fenômenos atuais, como as fakenews, a pós-verdade, o efeito bolha (a restrição de uma discussão a determinado grupo com o qual se compartilha algo, que dá a impressão de que não há discordância) requerem o desenvolvimento de habilidades novas no uso da linguagem, como a curadoria (seleção de informação), réplicas diversas de textos (remidiações, adaptações, etc.). Igualmente, o professor precisa se apropriar desses conceitos e procedimentos para contribuir com a formação de seu aluno.

Dessa forma, para que a BNCC alcance a sua sugestão de uma educação mais indisciplinar (MOITA LOPES, 2011), o trabalho com as práticas de linguagem deve ser mais ativo e mais significativo para os alunos, assegurando-lhes a utilização de diferentes mídias dentro e fora das escolas, pois as condições sociais presentes impõem formas de aprendizagem e socialização virtual que requerem habilidades tecnológicas. 


\section{REFERÊNCIAS}

BAKHTIN, M. (VOLOSHINOV). Marxismo e filosofia da linguagem: problemas fundamentais do método sociológico na ciência da linguagem. Tradução de Michel Lahud e Yara Frateschi Vieira; com a colaboração de Lúcia Teixeira Wisnik e Carlos Henrique D. Chagas Cruz. 2. ed. São Paulo: Hucitec, 1981.

Estética da criação verbal. Tradução de Paulo Bezerra. 6. ed. São Paulo: Martins Fontes, 2011.

BRASIL. Constituição da República Federativa do Brasil de 1988. Brasília, DF: Presidência da República, 1988. Disponível em: $<$ http://www.planalto.gov.br/ccivil_03/constituicao/constituicaocompilado.htm>. Acesso em: 23 jan. 2020.

Lei $\mathrm{n}^{\circ}$ 9.394, de 20 de dezembro de 1996. Estabelece as diretrizes e bases da educação nacional. Diário Oficial da União: República Federativa do Brasil: Poder Legislativo, Brasília, DF, $1996 . \quad$ Disponível em: $<$ http://www.planalto.gov.br/ccivil_03/leis/L9394.htm>. Acesso em: 23 jan. 2020.

Parâmetros Curriculares Nacionais: primeiro e segundo ciclos do ensino fundamental: Língua Portuguesa. Brasília, DF: MEC/SEF, 1998. Disponível em: $<$ http://portal.mec.gov.br/seb/arquivos/pdf/portugues.pdf $>$. Acesso em: 10 jan. 2020.

- Parâmetros Curriculares Nacionais: terceiro e quarto ciclos do ensino fundamental: Língua Portuguesa. Brasília, DF: MEC/SEF, 1998. Disponível em: <http://portal.mec.gov.br/seb/arquivos/pdf/portugues.pdf>. Acesso em: 10 jan. 2020.

Parâmetros Curriculares Nacionais: Ensino Médio. Brasília, DF: MEC/SEM, 1999. Disponível em: <http://portal.mec.gov.br/conaes-comissao-nacional-de-avaliacaoda-educacao-superior/195-secretarias-112877938/seb-educacao-basica2007048997/12598-publicacoes-sp-265002211 >. Acesso em: 10 jan. 2020.

. Resolução $n^{o}$ 2, de 30 de janeiro 2012. Define Diretrizes Curriculares Nacionais para o Ensino Médio. Brasília, DF, MEC/CNE/CEB, 2012. Disponível em: $<$ http://www.crmariocovas.sp.gov.br/Downloads/ccs/concurso_2013/PDFs/resol_federal_ 2_12.pdf>. Acesso em: 10 jan. 2020.

Lei 13.415/2017. Altera as Leis n ${ }^{\circ}$ 9.394, de 20 de dezembro de 1996, que estabelece as diretrizes e bases da educação nacional, e 11.494, de 20 de junho 2007, que regulamenta o FUNDEB, a Consolidação das Leis do Trabalho - CLT, aprovada pelo Decreto-Lei $\mathrm{n}^{\circ}$ 5.452, de $1^{\circ}$ de maio de 1943, e o Decreto-Lei $\mathrm{n}^{\circ} 236$, de 28 de fevereiro de 1967; revoga a Lei $\mathrm{n}^{\circ} 11.161$, de 5 de agosto de 2005; e institui a Política de Fomento à Implementação de Escolas de Ensino Médio em Tempo Integral. Brasília, DF: Presidência da República, Diário Oficial da União, 2017. Disponível em: $<$ http://www.planalto.gov.br/ccivil_03/_Ato2015-2018/2017/Lei/L13415.htm>. Acesso em: 09 abr. 2020. 
Base Nacional Comum Curricular: Ensino Médio. Brasília, DF: MEC/SEM, 2018. Disponível em: <http://basenacionalcomum.mec.gov.br/\#/site/inicio >. Acesso em: 10 jan. 2020.

COURTINE, J. J. Os deslizamentos do espetáculo político. In: GREGOLIN, M. do R. (Org.). Discurso e mídia: a cultura do espetáculo. São Carlos: Claraluz, 2003, p. 21-34.

FOUCAULT, M. Verdade e poder. In: Machado. 26. ed. São Paulo: Graal, 2013, p. 35-54.

. Microfísica do poder. Trad. Roberto

GOMES, R. Gêneros multissemióticos e ensino: uma proposta de matriz de leitura. In: Trem de Letras, v.3, n.1, Alfenas, MG, 2017, p. 56-80. Disponível em: $<$ https://publicacoes.unifal-mg.edu.br/revistas/index.php/tremdeletras/article/view/691>. Acesso em: 09 abr. 2020.

JENKINS, H. Cultura da convergência: a colisão entre os velhos e novos meios de comunicação. Tradução de Susana Alexandria. 2. ed. São Paulo: Aleph, 2009.

LAKATOS, E. M. Fundamentos de metodologia científica. São Paulo: Atlas, 2003.

MARCUSCHI, L. A. Produção textual, análise de gêneros e compreensão. São Paulo: Parábola Editorial, 2008.

MILANEZ, N. Estratégias do discurso: modos de enunciar a si em gifs de filmes de horror. In: GARCIA, F.; REIS, C.; SANTOS, A. C.; BATALHA, M. C.; FRANÇA, J.; MICHELLI, R. (Orgs.). As personagens nos mundos possíveis do insólito ficcional. Rio de Janeiro: Dialogarts, p. 115-129, 2018.

MOITA LOPES, L. P. da. Fotografias da Linguística Aplicada no Campo de Línguas Estrangeiras no Brasil. D.E.L.T.A., v. 15, ${ }^{\circ}$ especial, Campinas, SP, 1999, p. 419-435. Disponível em: <http://www.scielo.br/pdf/delta/v15nspe/4024.pdf > Acesso em: 10 mar. 2020.

. Da aplicação Linguística à Linguística Aplicada Indisciplinar. In: PEREIRA, R. C.; ROCA, P. (Orgs.). Linguística Aplicada: um caminho com diferentes acessos. São Paulo: Contexto, p. 11-24, 2011.

SAUSSURE, F. Curso de Linguística Geral. São Paulo: Cultrix, 1988.

SEVERINO, A. J. Metodologia do trabalho científico. São Paulo: Cortez, 2007.

SOARES, M. Português na escola: história de uma disciplina curricular. In: BAGNO, Marcos (Org.). Linguística da Norma. São Paulo: Loyola, p. 155-177, 2002.

SOUSA, C. As relações dialógicas na produção de memes na internet. In: Littera Online, v. $1, \quad \mathrm{n}^{\mathrm{o}} 20$, São Luís, p. 1-15, 2015. Disponível em: $<$ http://www.periodicoseletronicos.ufma.br/index.php/littera/article/view/3561/1597>. Acesso em: 09 abr. 2020. 
VASCONCELLOS, C. S. Planejamento: projeto de ensino-aprendizagem e projeto político-pedagógico. 9. ed. São Paulo: Libertad, 2000.

ZABALA, A. A prática educativa: como ensinar. Porto Alegre: Artmed, 1998.

Recebido em: 09 abr. 2020. Aceito em: 05 out. 2020. 